\title{
Mixed methods evaluation \& teaching with Guatemalan traditional midwives' regarding nursing interventions to manage postpartum hemorrhage
}

\author{
Kimberly Susanne Garcia \\ Bradford Regional Medical Center, USA \\ Correspondence: Kimberly Susanne Garcia. Address: 46 Stone Ave. Bradford, PA 16701, USA. Email: ksg11@case.edu. \\ Received: November 12, 2012 \\ Accepted: December 12, 2012 Online Published: April 11, 2013 \\ DOI : $10.5430 /$ jnep.v3n10p120 \\ URL: http://dx.doi.org/10.5430/jnep.v3n10p120
}

\section{Abstract}

Purpose: The purpose of this pilot descriptive study was twofold: to explore Guatemalan traditional midwives' knowledge, attitudes and practices about nursing interventions to manage postpartum hemorrhage (PPH), and to evaluate the effect of a culturally sensitive teaching on traditional midwives' knowledge of nursing interventions to manage PPH.

Methods: Thirteen midwives participated in a one-day teaching at a Refuge International Health Clinic in the remote town of Sarstun, Guatemala. The quasi experimental study used a one-group, pretest posttest design. Researchers relied on a PPH checklist from the American College of Nurse Midwives (ACNM) to evaluate knowledge of PPH interventions before and after the PPH teaching. One 45-minute focus group also was conducted among the midwives. The Long Table Approach was used to develop a matrix of common themes.

Results: The culturally sensitive teaching improved traditional midwives' knowledge and skills about nursing interventions to manage PPH (pretest $\mathrm{M}=1.385 / 8$, posttest $\mathrm{M}=4.846 / 8$ ). In the focus group, midwives revealed several themes that contradicted the literature. Midwives repeatedly denied managing PPH despite a combined 197 years of midwifery experience. Midwives said they trusted local health care providers, and would transfer patients to hospitals in emergencies. Midwives asked for assistance in educating villagers about the importance of prenatal care and of seeking early labor support.

Conclusions: Results of this pilot project suggest a culturally sensitive oral teaching in the primary language of participants improves traditional midwives' ability to manage PPH. Future training should follow a similar format to address the needs of illiterate participants in resource-poor settings, and should include the entire community, not just midwives.

\section{I ntroduction}

Postpartum hemorrhage (PPH) is the primary cause of maternal death worldwide, comprising 25\% all maternal deaths each year ${ }^{[1]}$. PPH is also the leading cause of maternal death in Guatemala, accounting for $53.3 \%$ of maternal deaths annually ${ }^{[2]}$. One factor contributing to maternal deaths from PPH is that Guatemalan traditional midwives, who attend most births, are unfamiliar with basic nursing skills to manage $\mathrm{PPH}{ }^{[3,4]}$. The government has been providing training 
programs for midwives since 1955. However, research shows that cultural insensitivity in government training programs has hindered a change in traditional midwives' ability to manage $\mathrm{PPH}^{[5,6]}$.

Cultural insensitivity in government training programs manifests in multiple ways. First, government training programs isolate traditional midwives' from the training group by criticizing traditional midwife practices ${ }^{[5,7]}$. Additionally, training programs are conducted in Spanish with written materials without consideration that most traditional midwives are illiterate and speak Maya dialects ${ }^{[4,8]}$. Finally, government training programs are based on a medical model recommended by the World Health Organization ${ }^{[9]}$ that relies on oxytoxic medications for uterine contractions and on transferring patients to hospitals for obstetrical emergencies ${ }^{[5,10]}$. Most traditional midwives cannot practice a medical model because many live in remote areas that lack reliable and timely resources, such as oxytoxic medications, and transportation to hospitals ${ }^{[11]}$. Some indigenous patients also refuse hospitals transfers because they distrust hospital providers $^{[4,12,13]}$.

In order to change Guatemalan traditional midwives' ability to manage PPH, we must first understand: what traditional midwives already know about PPH; what practices, if any, they use to manage PPH; and what their attitudes are toward accepting new practices to manage PPH. A paucity of data exists in the literature related to traditional midwives' knowledge, practices and attitudes about PPH. The purpose of conducting a focus group with Guatemalan traditional midwives was to explore their knowledge, practices and attitudes regarding PPH to better inform future teachings. The questions asked focused on traditional midwives' experience with PPH, on their exposure or lack thereof to oxytocin, and on patient transportation to hospitals. Focus group questions also examined traditional midwives' attitudes toward the medical model and knowledge about PPH management.

Madeline Leininger's Cultural Care Theory suggests people are more willing to take in etic knowledge from outside their cultural once they have shared emic knowledge from inside their culture ${ }^{[14]}$. After midwives shared emic knowledge in the focus group, midwives attended a culturally teaching about etic nursing interventions to address PPH. Nursing interventions were based on a Home Based Life Saving Skills (HBLSS) curriculum the American College of Nurse Midwives (ACNM) has developed and field tested in several third world countries with great success ${ }^{[15-18]}$. Midwives were given a pretest and posttest based on a PPH Checklist from the ACNM. The purpose of the checklist was to assess and compare midwives' knowledge of PPH interventions before and after the PPH teaching.

\section{Methods}

This pilot descriptive study used both qualitative and quantitative measures to facilitative a broader understanding of traditional midwives' ability to manage PPH.

\subsection{Setting}

This one-day pilot project was held at a Refuge International Health Clinic in the remote village of Sarstun, located on the Sarstun River, the boundary between Guatemala and Belize, in the eastern central part of Izabal. Refugee International is a nonprofit organization two Texas nurses founded in 2001. The organization has four clinics in Guatemala, including one in Sarstun, which is one of the most remote areas in Guatemala and has some of the poorest health conditions in the country.

No roads lead in or out of Sarstun. Visitors access the community by taking a two-hour boat ride from Puerto Barrios, the capital city of Izabal. The Sarstun health clinic is housed in a 3,000-square-foot stucco building with a thatched roof. The health clinic has running water, electricity, bathrooms, and showers. The first floor has a pharmacy, two operating rooms, and six examination rooms. The second floor has three private bedrooms, a large, covered open-air area that sleeps 50 guests comfortably and a 12 by 18 foot conference room where the focus group and teaching were held. 


\subsection{Sample}

The Refuge Clinic serves three lowland and six highland villages. Refugee International volunteers invited all traditional midwives from highland and lowland villages to attend the focus group and teaching program. Refuge International volunteers have established relationships with these these midwives for the past 12 years. A Refugee International boat provided transportation for nine midwives who came down from three highland villages to attend the the focus group and teaching program. Four midwives from two lowland towns walked a short distance to the clinic. The average age of the midwives was $44.54+/-6.489$ years. Participants had practiced midwifery for a mean of 13.42 +/- 9.02 years. Sixty-nine percent spoke Kek Chi, 15\% spoke Spanish, and 15\% spoke both languages. Three midwives were literate. Average years of formal education was $1.3+/-1.991$ years. All midwives reported feeling valued in their communities. Nearly one-third of the midwives stated they became midwives after attending a neighbor's birth, $23.1 \%$ by village election, and $23.1 \%$ by apprenticeship. Only $7.7 \%$ of participants stated they were spiritually called to midwifery, but the calling was a secondary path instead of the primary path to becoming a midwife.

\subsection{Procedure}

Midwives were informed when they arrived at the clinic at 8 a.m. of the purpose of the study and invited to complete a Background Data Sheet. Midwives were told their participation was voluntary, participation was considered consent and discussions would be audio-taped. An Institutional Review Board exempted signed consents. The focus group discussion was conducted among 13 midwives with two translators who spoke Kek Chi and Spanish, and were also midwives. While 10 to 12 participants is ideal for a focus group, an estimate was unknown of how many midwives would travel the distance for the focus group. No midwives were turned away as the teaching was a unique opportunity to disseminate necessary health information.

The Primary Investigator (PI), a trained and experienced moderator, met with both translators before the focus group to explain the process. The PI was a U.S. midwife educated in Central American history, politics and culture. The PI led the discussion in Spanish, posing open-ended questions about traditional midwives' practices. Translators then translated questions verbatium into Kek Chi. Participants were invited to share stories about questions asked. Translators then translated into Spanish summaries of what participants shared during the focus group so the PI could follow the discussion. The PI probed further if more information could be gained or if midwives' statements were unclear.

After the focus group, each midwife completed the pretest by performing on a female volunteer steps she would take to manage PPH. A research assistant observed the demonstration and checked off steps the participant performed on the PPH Checklist. After a one-hour teaching based on the HBLSS curriculum, midwives answered a Demographic Data Sheet and completed the posttest by again demonstrating on a volunteer steps for addressing PPH. Three hours passed between the pretest and posttest. The research assistant marked on the PPH Checklist skills midwives performed. To thank midwives for participating in the focus group and teaching, researchers presented midwives with medical supplies, such as blue towels, iodine, examination gloves, and umbilical cord tape. Researchers also gave midwives laminated cards with pictures demonstrating the steps to manage PPH as reminders, and asked midwives to make mental notes of cases of PPH they encountered in the coming months. Researchers plan to ask midwives to share information about experiences using their new ability to manage PPH during the next Sarstun. Volunteers then served midwives a meal and transported them by boat at 4 p.m. back to their respective return sites on the foot of the mountain.

\section{Steps Taught and Tested on Pretest and Posttest from Modified PPH Checklist from the ACNM}

1) Call for help

2) Help squat, pass urine

3) Rub womb

4) Place baby on breast to nurse

5) Roll nipples 
6) Put baby skin to skin with mom

7) Do two-hand hold of uterus

8) Put pad firmly between legs

9) Put nothing in birth canal

10) Refer to hospital

\subsection{Data collection}

Focus group discussions were audio-recorded for accuracy. In addition, the PI and a U.S. Registered Nurse (RN), who has worked five years at a Guatemala hospital, took field notes to highlight group agreement to individual comments, voice inflection, and statements that held significance. Audiotapes were translated and transcribed according to Breslin's methods of translation ${ }^{[19]}$. A U.S. RN who worked for 20 years with the Kek Chi in an area north of Sarstun transcribed audiotapes. This RN speaks fluent Kek Chi, Spanish, and English. The PI, who is fluent in Spanish, reviewed audiotapes from the focus group to check accuracy of the U.S. RN's translations from Spanish to English. Breslin's method of translation guided issues with translations.

The quantitative arm of the study used three instruments: the PPH Checklist, a Background Data Sheet and a Demographic Data Sheet. The PI added skin-to-skin contact between mother and newborn starting immediately after birth to the PPH Checklist. The UNICEF/WHO ${ }^{[27]}$ strongly recommended skin-to-skin care and breastfeeding within the first hour after birth in the Baby Friendly Hospital Initiative. Skin-to-skin care promotes release of maternal oxytocin ${ }^{[20]}$, which encourages uterine involution. The PI designed the background and demographic data sheets based on a literature search about PPH and Guatemalan traditional midwives. A judge panel of three experts established content validity of the data sheets with a Fog Index of 0.35 . The Fog Index measures the ease of reading a writing sample. The resulting number is a rough estimate of the number of years of formal education the reader should have to understand the test on first reading. In other words, readers with less than one year of education should be able to understand passages with a Fog Index of 0.35.

\subsection{Data analysis}

The Long Table Approach was used in consultation with three, senior nurse researchers to analyze English transcripts from the focus group to develop a matrix of categories and common themes (Krueger \& Casey, 2000). The Long Table Approach entails reviewing printed transcripts in entirety, cutting apart and sorting transcripts in categories of questions (Krueger \& Casey, 2000). Later, each question was summarized, and answers were compared and contrasted. A matrix of main topics was developed including identification and coding of key words and common themes. Bracketing and frequency of similar words and phrases helped in theme identification. The analysis conclusion identified common themes among all questions. Theme analysis was compared to field notes from researchers. Emergent themes were reported with supporting quotes from participants.

The quantitative arm of the study used frequencies and measures of central tendency to analyze demographic and background data. Performance scores from the PPH Checklist were the total number of steps marked as satisfactorily demonstrated on the pretest and posttest. The quantitative arm of the study measured change in level of knowledge as a comparison of mean pretest and posttest scores.

\section{Results}

\subsection{Pretest/ Posttest scores}

The mean pretest score was 1.385 +/-SD 0.870 (1.3). The mean posttest score was 4.846 +/- SD 0.899 (3-6). As the sample size in this study was not large enough to determine if this difference was significant, we are presenting only the mean raw scores, which clearly indicate a strong increase in knowledge after the educational intervention. 
Before the training most midwives demonstrated only one or two of the eight steps on the PPH Checklist. All of the midwives did fundal massage and one-third of midwives demonstrated a two-handed fundal hold. Before the teaching, midwives also massaged the patient's legs, lifted the patient's legs and gave the patient herbs to treat PPH, even though none of these interventions were on the PPH Checklist. The pretest responses offered insight into traditional midwives' practices in Guatemala.

After the culturally sensitive teaching, most midwives recalled five of the eight steps on the PPH Checklist. The two steps midwives most frequently forgot were "call for help" and "put nothing in the vagina." Midwives did not receive credit for the later step unless they stated they would "put nothing in the vagina." Research assistants randomly asked six midwives who did not verbalize they would "put nothing in the vagina" if they would put anything in the vagina, and all six answered they would not. Appropriate evaluation of this question was a limitation of the study.

\subsection{Focus group}

Four primary themes arose from focus group discussion. First, midwives repeatedly denied ever managing PPH, even when not directly asked. Second, midwives said they trusted local health care providers, and asserted they would transfer patients to hospitals. Third, midwives related that transportation to hospitals was a problem. Fourth, midwives stated their most immediate need was assistance educating villagers about the importance of prenatal care and of seeking early labor support.

\section{Denial of managing PPH}

PPH is the primary reason women die in childbirth, comprising half of maternal deaths (International Confederation of Midwives, 2009), yet midwives repeatedly denied managing PPH during focus group discussions, even when not directly asked.

One midwife introduced herself by saying, "I am 45 years old. I have been a midwife 23 years. I have delivered about 40 children, and thanks be to God, I have not had any problems. All the deliveries went well. All are alive.”

When asked if they had ever experienced bleeding too much after birth, only one midwife raised her hand in acknowledgement, and said she herself suffering a hemorrhage while giving birth.

Four other midwives declared throughout the discussion, even when they were not directly asked about PPH experiences, that they had never attended a hemorrhaging patient. One midwife said, "I have never seen this, but I have heard that some have had this happen.”

Another midwife said, “Sometimes in my community, women will have this problem, but they don’t tell anyone.”

One midwife denied attending to hemorrhaging during the focus group, and later told the PI privately she had helped one patient with PPH.

In fact, the last comment from a midwife during the focus group was a final denial of managing PPH during a discussion about another topic. She said, "I haven’t had any problems like you are talking about.”

\section{Trust in hospital providers}

Midwives asserted that they trusted local health care providers, and would transfer hemorrhaging mothers to local hospitals. If patients resisted hospital transfers, midwives said they would assuage patients' fears.

One midwife said, "When I have had something happen to a woman who was hemorrhaging, I massaged (her uterus). If they are still bleeding, I call the health promoter to give an IV (intravenous). We (midwives and health promoters) help each other." 
Four midwives said mothers sometimes fear going to the hospital, and they lack resources to pay for hospital care. One midwife said, "They are often afraid to go to the hospital or maybe the husband doesn't have enough money."

Another midwife commented, “People are afraid to go to the hospital. They don't want to go. They (patients) don’t speak Spanish. They (patients) don’t have money.”

Midwives viewed as part of their role offering mothers reassurance about the importance of hospital transfers in an emergency. One midwife said, "We tell them they may not have to have surgery. They may be able to deliver naturally. We tell them (health care professionals) will be able to help them at the hospital. Maybe they (mothers) have a sickness, and they (hospital providers) can give them the medicine they need."

\section{Transportation problems}

Midwives asserted that transportation to hospitals is unreliable, particularly because mothers lack resources. One midwife said, "The man of the house must start saving his money so that when there is a sickness, he will have money to take her to the hospital if necessary."

Another midwife added they have access to transportation, but arranging transportation not dependable. She said, "We have problems with transportation. We are using the boat launch near the Refuge Clinic.”

Only one midwife said she could afford access to reliable transportation. She commented, "When we have a problem like that (PPH) then we send for someone to pick them up by canoe and take them to the hospital."

\section{Help educating villagers}

Midwives stated their most pressing need is assistance educating villagers about preventing PPH, particularly men. Midwives said villagers lack understanding the importance of seeing a midwife at least once during their pregnancy and earlier in labor before problems start.

One midwife commented, "Sometimes in my community (women) are (laboring) by themselves in their houses. It is better to tell the man that he should call us. If he calls, this is a way we can help her, by transferring her to the hospital."

Another midwife added, "In my community the same happens. It is not until the hour of need that is when they call me. What was told to us in our study is that we (midwives) should be told when they (pregnant women) are five months pregnant. It is at that time the woman should be preparing herself. But if the baby is coming when they call on me to help, it is difficult. If she is already in danger, what can you do?”

\section{Discussion}

Information from demographic data underscored literature findings about traditional midwives, while focus group themes refuted literature findings. Demographic information regarding midwives' ages, years of experience, literacy and language concur with literature reports. Meanwhile, two focus group themes disagree with literature reports: midwives denied managing PPH and asserted they trusted hospital providers. Information from background data both confirmed and refuted literature findings. Traditional midwives denied being spiritually called to their practice, and said their communities valued their work.

Information from demographic data regarding literacy and Mayan dialect underscored literature reports regarding characteristics of Guatemalan traditional midwives ${ }^{[4,5,8]}$. Information concerning age and number of years of experience also confirmed with literature findings that midwives tend to be older and experienced ${ }^{[3,21,22]}$. Years as a midwife was a suspect result because participant midwives from the same villages said they had been midwives equal number of years. These findings beg the question whether traditional midwives can count, which is critical information for future teachings. 
An observation from background data that concurs with reports from other studies is that midwives are highly regarded in their communities ${ }^{[5,11]}$. Classic studies conducted 30 years ago suggested midwives were spiritually called to their practice and thus likely to reject interventions ${ }^{[21-23]}$. However, only one midwife who participated in this study said she felt spiritually called to midwifery. This observation coincides with a more finding that younger midwives were less likely to be spiritually called to their practice and thus more accepting of interventions ${ }^{[11]}$. A final important result from background data was all midwives said they felt valued during the teaching. Studies have reported midwives in government training programs felt humiliated, which impaired learning ${ }^{[5,8]}$.

Themes from focus group findings tended to refute literature findings. In regard to midwives denying experience with PPH, Maupin ${ }^{[24]}$ reported that lingering distrust and fear from a 26-year civil war hindered Guatemalans from embracing an integral, government health system. Schieber wrote that registration of maternal death is a sensitive matter in Guatemala, because sometimes a consequence is legal action against involved parties. Traditional midwives denying experience with hemorrages that contribute to postpartum maternal death may originate from cultural sensitivity about death.

PPH by definition is blood loss of $500 \mathrm{cc}^{[25]}$. Inability to distinguish between normal bleeding after birth and hemorrhage may be another factor contributing to midwives denial of experience with PPH. Even for well-educated birth attendants, midwives and physicians, estimating blood loss is not always accurate. For traditional midwives, who are mostly illiterate and have minimal education, estimating blood loss may be next to impossible if they cannot count and do not know how to quantify volume.

Another focus group theme that contradicted literature reports was midwives asserted they trusted local health promoters and hospital providers. Midwives have been taught in other training programs to transfer patients with obstetrical emergencies to hospitals, but implementation of this action is unknown. Actual transportation time to the nearest hospital may include a two-hour walk down the mountain followed by a two-hour motorboat ride.

Expense is an additional consideration for hospital transfer to treat hemorrhage. Boat launches near Sarstun cost 50 Quetzales or $\$ 6.25$ for the two-hour motorboat ride to the nearest hospital. The cost of this boat trip is equal to the average pay for two days ${ }^{[24]}$ even though many villagers are not employedt. In fact, finances are so limited near Sarstun that many midwives do not ask for payment for their services, underscoring what literature findings ${ }^{[10]}$ and what midwives repeated in the focus group. Instead, Kek Chi natives tend to rely on a barter system to exchange good and services rather than in a monetary system. Villagers elect midwives to their posts due to their special talents. Thus, midwives feel honored to hold their positions as public service ${ }^{[10]}$.

In addition to issues about transportation and money, if a hemorrhaging mother make the arduous trip from her village to the nearest hospital, hospital conditions bleak. The Guatemalan Ministry of Public Health and Social Welfare estimated $30 \%$ of primary health establishments, such as hospitals, need new medical equipment and building reconstruction ${ }^{\text {[26] }}$.

Reports that differ from literature findings state social desirability may have influenced focus group discussions. Emergent themes from this pilot study provide an overview of the collective experience of traditional midwives from remote areas in rural, central eastern Guatemala. However, these results cannot be generalized to midwives in more educated, urban, areas, such as Guatemala City where 20\% of the populations resides.

Positive attributes of this study include matching the theory and goals underlying the research, and offering the intervention to all participants at the same time. Future studies are necessary with this population, and should include more creative testing methods including whether midwives can receive credit when asked about putting anything in the vagina, can look at Take Action Cards during the posttest, and can have props, such as sanitary napkin pads and babies, during the pre and posttest. 


\section{Conclusion}

Results from both the quantitative and qualitative studies have implications for nursing. As Leininger's theory suggests, worldview holds a significant impact on cultural care meanings, expressions and patterns ${ }^{[14]}$. Several findings from the focus group conflict with literature findings, and midwives offered new insights not previously reported in the literature. Thus, findings from this focus group provide better information for future studies about working within the worldview of rural, central-eastern Guatemalan midwives to impact their cultural care pattern of managing PPH.

The quantitative arm of this study shows that nurses who develop culturally sensitive educational programs intended to improve maternal health in resource-poor areas can have a valuable influence on knowledge. If this knowledge renders improved behaviors, nurses can serve as a force in changing the objectionable maternal mortality and morbidity rates in third world countries. Traditional midwives can be taught to use their hands to perform nursing interventions for managing PPH rather than depending on medical model interventions that require resources, such as medications and transportation, which are unavailable to most traditional midwives. Additionally, traditional midwives felt valued during culturally sensitive instruction. Participants feeling valued should bolster retention of educational content as well.

Results of this project underscore reports from Lang and Elkin's study ${ }^{[3]}$ that recommends changing traditional midwives' knowledge by providing culturally sensitive teaching in an oral format in the primary language of participants. Findings of this project also coincide with evidence the ACNM has documented from implementing the HBLSS in India ${ }^{[16]}$, Ethiopia ${ }^{[17,18]}$ and Bangladesh ${ }^{[15]}$. The ACNM has positively changed knowledge among traditional birth attendants in other third world countries by offering oral teachings from the HBLSS is the primary language of participants.

The HBLSS curriculum that underpins this project encompasses 12 topics on preventative and lifesaving skills to treat moms and babies. Prevention of PPH was just one of the units. Offering other topics from the HBLSS curriculum in a culturally sensitive manner as described in this project may further address Guatemala's unacceptably high MMR and Infant Mortality Rate (IMR). Guatemala’s MMR is 156 to 270 deaths per 100,000 live births ${ }^{[4]}$. The IMR is 51 to 100 deaths per 1,000 live births ${ }^{[3]}$. Dedicated nurses and midwives plan to continue bringing interventions and research to low-resource areas where women and babies are at high risk for poor outcomes.

\section{References}

[1] Outlook. 2009. Preventing postpartum hemorrhage. Managing the third stage of labor. Available from: www.whiteribbonalliance.org/Resources/Documents/Preventing\%Postpartum\%20Hemorrhage_PATH.pdf.

[2] International Confederation of Midwives. 2009. Active management of the third stage of labor. Available from: http://pphprevention.org/files/Guatemalafinalreport.pdf.

[3] Lang, J. B., \& Elkin, E. D. A study of the beliefs and birthing practices of traditional midwives in rural Guatemala. Journal of Nurse Midwifery. 1997; 42 (1): 25-31.4. http://dx.doi.org/10.1016/S0091-2182(96)00069-9

[4] Roost, M. \& Johnsdotter, S., Liljestrand, J., \& Essen, B. A qualitative study of conceptions and attitudes regarding maternal mortality among traditional birth attendants in rural Guatemala. British Journal of Obstetrics \& Gynaecology. 2004; 111(2): 1372-1377. http://dx.doi.org/10.1111/j.1471-0528.2004.00270.x

[5] Goldman, N., \& Glei, D. A. Evaluation of midwifery care: Results from a survey in rural Guatemala. Social Science \& Medicine. 2003; 56 (4): 685-700. http://dx.doi.org/10.1016/S0277-9536(02)00065-5

[6] Greenberg, L. Midwife training programs in highland Guatemala. Social Science \& Medicine. $1982 ; 16$ (18): $1599-1609$. http://dx.doi.org/10.1016/0277-9536(82)90290-8

[7] Walsh, L. V. Beliefs and rituals in traditional birth attendant practice in Guatemala. Journal of Transcultural Nursing. 2006; 17: 148-154. PMid:16595402 http://dx.doi.org/10.1177/1043659605285412

[8] Hinojosa, S. Z. Authorizing tradition: vectors of contention in highland Maya midwifery. Social Science \& Medicine. 2004; 59 (3): 637-651. PMid:15144771 http://dx.doi.org/10.1016/j.socscimed.2003.11.011

[9] World Health Organization (2009). WHO guidelines for management of postpartum haemorrhage and retained placenta. Available from: whqlibdoc.whoint/publications/209/9789241598514_eng.pdf. 
[10] Maupin, J. N. Remaking the Guatemalan midwife: health care reform and midwifery training programs in highland Guatemala. Medical Anthropology. 2008; 27 (4): 353-8. PMid:18958785 http://dx.doi.org/10.1080/01459740802427679

[11] Cosminsky, S. Midwifery training across the generations: A modernizing midwife in Guatemala. Medical anthropology. 2001; 20 (4): 345-78. PMid:11817850 http://dx.doi.org/10.1080/01459740.2001.9966198

[12] Berry, N. S. Kaqchikel midwives, home births, and emergency obstetrical referrals in Guatemala: Contextualizing the choice to stay home. Social Science \& Medicine. 2006; 62 (8): 1958-69. PMid:16225975 http://dx.doi.org/10.1016/j.socscimed.2005.09.005

[13] Berry, N.S. Who's judging the quality of care? Indigenous Maya and the problem of not being attended. Medical Anthropology. 2008; 27 (2): 164-189. PMid:18464128 http://dx.doi.org/10.1080/01459740802017413

[14] McFarland, M. Madeline Leininger 1920 to present: Cultural care theory of diversity and universality. In M. R. Alligood and A. M. Toomey (6th ed.). Nursing Theorists and Their Work (pp. 427 - 496) St. Louis, MO: Mosby Elsevier. 2006.

[15] Dynes, M., Rahman, A., Beck, D., Moran, A., Rahman, A., Pervin, J., Yunus, M., Rashid, M. H., Gazi, T., Kanti Bismas, K., Buffington, S., Patteron, J. M., \& Sibley, L. Home based life saving skills in Matlab, Bangldesh: A process evaluation of community-based maternal child health programme. Midwifery. 2009: 9-25-09, epub.

[16] Fullerton, J. T., Killian, R., \& Gass, P. M. Outcomes of a community and home-based interventions for safe motherhood and newborn care. Health Care for Women International. 2005; 26 (7): 561-76. PMid:16126600 http://dx.doi.org/10.1080/07399330591004881

[17] Sibley, L., Buffington, S. T., \& Haileyesus, D. The American College of Nurse Midwives’ home-based lifesaving skills program: a review of Ethiopia field test. Journal of Midwifery and Women’s Health. 2004; 49 (4): 320-8. PMid:15236712 http://dx.doi.org/10.1016/j.jmwh.2004.03.013

[18] Sibley, L., Buffington, S. T., Tedessa, L., \& McNatt, K. Home-Based Life Saving Skills in Ethiopia: an update on the second phase of field testing. Journal of Midwifery and Women’s Health. 2006; 51 (4): 284-91. PMid:16814224 http://dx.doi.org/10.1016/j.jmwh.2005.10.015

[19] Yu, D. S., Lee, D. J., \& Woo, J. Translation of chronic heart failure questionnaire. Applied Nursing Research. 2003; 16: 278-283. PMid:14608561 http://dx.doi.org/10.1016/j.apnr.2003.08.005

[20] Matthiesen, A. S., Ransjo-Arvidson, A. B., Nissen, E., \& Uvnas-Moberg, U. Postpartum maternal oxytocin effects of infant hand massage and sucking. Birth. 2001; 28 (1): 13-19. http://dx.doi.org/10.1046/j.1523-536x.2001.00013.x

[21] Paul, L. Recruitment to a ritual role: the midwife in a Maya community. Ethos. 1975; 3(3): 449-47. http://dx.doi.org/10.1525/eth.1975.3.3.02a00050

[22] Paul, L., \& Paul, B. D. The Maya midwife as sacred specialist: a Guatemalan case. American Ethnologist. 1975; 2 (4): 707-25. http://dx.doi.org/10.1525/ae.1975.2.4.02a00080

[23] Cosminsky, S. Childbirth and midwifery on a Guatemalan finca. Medical Anthropology. 1977; 1 (3): 69-104. http://dx.doi.org/10.1080/01459740.1977.9965825

[24] Maupin, J. N. 'Fruit of the accords': healthcare reform and civil participation in Highland Guatemala. Social Science Medicine. 2009; 68 (8): 1456-68. PMid:19246145 http://dx.doi.org/10.1016/j.socscimed.2009.01.045

[25] Varney, H., Kriebs, J. M., \& Gegor, C. L. Varney’s Midwifery. (4th ed.). Sudbury, Mass: Jones and Bartlett Publishers. 2004.

[26] Medical Mission Exchange. 2002. Guatemala. Available from: www.mmex.org/PAHOGuatemala.Rpt.pdf.

[27] UNICEF/WHO. Baby friendly hospital initiative revised, updated and expanded for integrated care, Section 1, Background and Implementation. 2009. Available from: www.unicef.gr.pdf/mdg2007.pdf. 